ELORE (ISSN 1456-3010), vol. 17 - 2/2010.

Julkaisija: Suomen Kansantietouden Tutkijain Seura ry.

[http://www.elore.fi/arkisto/2_10/frog2_2_10.pdf]

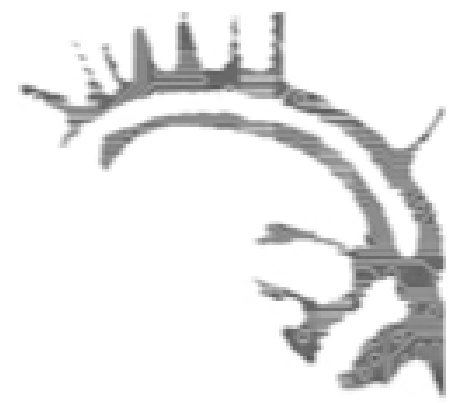

Book Review

\title{
Windows INTO OTHER WORLDS
}

Vaitkevičienè, Daiva (ed.) 2009: Lietuviu užkalbëjimai: Gydymo formulès - Lithuanian Verbal Healing Charms. Vilnius: Lietuviu literatūros ir tautosakos institutas. 919 pages.

$\underline{\text { Frog }}$

The early twentieth century was an era which saw massive efforts to organize and collate the contents of enormous folklore archives. Riding on the coat-tails of Romanticism, these efforts extended to organizing the publication of the collections - or representative samplings thereof - in a format appropriate for folkloristic and linguistic research. These efforts produced a wealth of resources that have maintained a central position in research up to the present day. Now, just as we crossed the threshold into the twenty-first century, so too have many of these resources been crossing the threshold into digital media. Although these publications and their more recent virtual equivalents have made the corpora themselves increasingly available, the language barrier remains an enormous obstacle for scholars interested in accessing these sources for comparative research. Daiva Vaitkevičienè has taken a major step in overcoming this problem through the publication of the corpus of Lithuanian healing charms with accompanying translations in English.

\section{INTRODUCTION TO THE TRADITION}

Anyone who is interested in Lithuanian charms - or any charm traditions in the Circum-Baltic or Northern Europe more generally - should make themselves familiar 
with Vaitkevičienës introduction. The introduction appears in both Lithuanian (57 pages) and English (much lighter on examples: 36 pages). It is clearly articulated, well-organized and rich with information. Lithuanian healing charms are introduced in relation to similar vernacular genres and then to traditions of other cultures before providing an excellent overview of conventions of transmission and aspects of performance. Of course, this is in addition to providing an introduction to the corpus itself, the history of collection, its documentation and tradition bearers, as well as a map, tables and thirty-two photographs.

\section{Organization of the Corpus}

The corpus includes 1716 charm texts accompanied by accounts of performative action and supplementary comments by informants - in addition to the practical archival data. This collection is exceptional because it includes the nearly two hundred charms collected from Lithuanian charmers in other languages, such as Russian and Polish (items 1531-1716). These charms have been omitted from earlier collections of Lithuanian charms, yet they are essential for understanding the charm tradition, with its relationships to and interactions with traditions of other languages and cultures. In the most basic capacity of making the corpus available, Lietuvin užkalbejimai immediately reveals itself to be an exceptional resource.

The corpus is organized according to what Vaitkevičienè calls "narrative functions". This is a typological strategy of organization which focuses on the schema underlying charms in application. Organization by narrative function might be loosely described as organizing the corpus around how charms are supposed to 'work' - i.e. the syntactic structure according to which the charm functions within the semiotics of the healing rite as a process. Vaitkevičienè compares her account of narrative functions to Vladimir Kliaus's organization of Slavic verbal charms according to "plot themes". However, Vaitkevičienè emphasizes that "in Lithuanian charms the actions presented rarely are developed into plots" (p. 78).

All previous collections of Lithuanian charms have been organized according to what the charm is intended to heal or 'do', subordinating structural typologies to application. Typologies according to application lead to the dispersal of examples of a conventional historiola or crystallized verbal sequences which have more than one use. Similar issues arise from classification according to structural-semantic charmtype, which tends to demand increasing levels of interpretation on the part of a researcher concerning how a specific textual product relates to ideal categories in a field of actual variation and realities of brief or fragmentary examples, including 'mixed' types. Vaitkevičienè accommodates these interests by including indices at the conclusion of the volume (pp. 860-864, 865-867), as well as by including in the introduction an overview of applications and charm-types encountered in the tradition (pp. 23-26, 76-78). Indices of informants, collectors and locations, as well as a glossary of unusual terms are also included. Unfortunately, the indices are not 
Frog: Windows into Other Worlds

translated and can therefore be challenging to a reader unfamiliar with Lithuanian.

\section{Translations of a Corpus}

Translations are compiled as a unified section following the corpus. Rather than the whole corpus, select examples of each charm-type under each narrative function are translated. Information on the informant, collector, location, etc., is not reduplicated with the translation. In a publication which is over 900 pages long, selective translation appears to be largely a function of space, which also appears to underlie the lack of translations of charms in other languages (sections XI-XII). Although the translations are selective, it remains easy to gain a practical perspective on the corpus. Several hundred examples have been translated, making it possible to develop a general overview of the charm tradition. I found this a very practical solution to translating a corpus which makes it easy to observe the relationship of a type to the corpus whole. For example, a single example of "Sun Walks under the Heavens and Doesn't Hurt Anyone" appears in translation (item 1084), followed by two examples of "Little Gold, Little Silver, Go Home and Lie Down!" (items 1086 \& 1091). Flipping back to the original texts reveals that item 1084 is the only example of the first, while there are nine examples of the second (items 1085-1093). In addition, reading the translations had the advantage of acquiring a rapid overview of the entire corpus without getting overwhelmed by, for example, 170 examples of "New Moon, a Full Turn for You, for Me My Health": ten selected examples and knowledge of 160 more proved quite sufficient!

\section{"Narrative Functions" and Lithuanian Healing Charms}

Organization according to narrative function does not eliminate cases in which an interpretation is required of the researcher. However, this approach seems to reduce problems of other systems and is perhaps better-suited to the Lithuanian charm tradition, which does not appear inclined to integrate multiple narrative functions into a single extended sequence. More importantly, classification according to narrative function shifts emphasis from charms as dislocated 'texts' to the verbal text of the charm within the context of a healing rite as a whole. According to Vaitkevičiené " $[t]$ he repertoire of Lithuanian charms falls within the framework of eleven narrative functions," some of which are closely paired or oppositional (p. 78). This can be contrasted with the thirty-two "plot types" in Kliaus's index of Slavic charms. Following Vaitkevičienès organization, the eleven narrative functions are:

Separation - used in a refined sense of negating the connection between the illness and the patient, or negating its potency or existence within the patient

Connection - the opposite of separation: healing is accomplished through the joining 
Frog: Windows into Other Worlds

of disconnected or broken parts

Expulsion - separation with a directional orientation

Transmission - expulsion involving transference to a new subject

Reciprocation - transmission with requests/demands that lost positive qualities be returned

Purification - removal through cleansing processes

Destruction - causing disappearance/destruction without separation or expulsion

Locomotion - movement intended to maintain or restore natural order (in a broad sense including the successful accomplishment of bodily processes such as childbirth)

Cessation - opposed to locomotion: terminating processes such as blood-flow, etc. Designation - a type defined not by action, but by object: the identification of the illness, illness agent, and/or the being that engendered it or could have done so Redemption - requesting aid and accomplishing the healing act via an intermediary

Healing magic based on writing and canonical prayers spoken in the place of charms are presented in separate sections. Vaitkevičienè includes statistics on the relative distribution of both recorded charm-types and individual recorded charms across these narrative functions - e.g. separation accounts for ca. $6 \%$ of types, $8 \%$ of variants (pp. 27, 79). This classification strategy offers insights into the conceptual system underlying magical practices. For example, 'bone to bone' charms appear to belong to the Indo-European heritage and were widely used across linguistic-cultural groups in northern Europe. Lithuanian is considered exceptionally conservative as an Indo-European language, yet there is only a single example of a 'bone to bone' charm in the corpus (pp. 27, 79-80; item 121, recorded in 1968). This paucity of examples contrasts with the conservatism of the Lithuanian language as well as with the widespread use of charms of this type in surrounding Slavic, Finnic and Germanic cultures. The historiola (of the so-called Second Merseburg Charm -type) associated with 'bone to bone' charms in northern Europe is also encountered in the corpus, but not with the 'bone to bone' healing words - it seems to have been adapted into the system of cessation charms, i.e. adapted to a different narrative function as a healing strategy (item 970; cf. items 996-1000).

Vaitkevičienës organization of the corpus by narrative function reveals that the single example of the 'bone to bone' charm is the only example of a connection charm. This implies that there is a relationship between the lack of evidence of the 'bone to bone' charms and basic conceptual patterns underlying magical healing: uniting or reuniting things in a process of connection seems to have simply lacked a place in the conceptual system associated with healing, or may even have been contradictory to preferred narrative functions which remove or destroy the agent (cf. pp. 35, 85-86). This is still more interesting in light of multilingual charmers, owing to the clear interaction with charming traditions in which connection charms were established, although the vernacular conceptual system seems to have inhibited these connection charms from gaining a foothold in the tradition. Approaching charms in 
terms of narrative function can offer significant insights into cultural patterns and their conceptual systems, opening significant new directions for future research.

\section{Windows INTO OTHER WorLdS}

Lietuviu užkalbejimai does not simply present a sample or selection of charms: it is a corpus. As a corpus, it offers more than selective glimpses into another tradition: it offers a window into another world. As a corpus, it allows perspective. If the 'bone to bone' charm were to appear in a selection of Lithuanian charms, we would naturally assume that it was representative of the Lithuanian 'tradition', reflecting either an Indo-European or Circum-Baltic heritage. Vaitkevičienè has banished that risk by providing us with a full corpus, and I for one am thankful. Lithuanian language and culture holds a central position for comparative research in Indo-European studies. In addition, the Circum-Baltic area is receiving increasing attention as an arena of cultural contact and exchange with a long and dynamic history relevant to the study of a wide range of linguistic and cultural phenomena. Vaitkevičienès publication takes a significant step in overcoming the most challenging obstacle to comparative research: the language barrier. If the early $20^{\text {th }}$ century saw massive efforts to organize and collate archives and make those collections internationally accessible in print, perhaps Vaitkevičienè stands at the forefront of a movement for the emerging century - a movement which will enable these collections to bridge the language barrier.

PhD Frog is a research fellow at the Department of Folklore Studies, University of Helsinki. 